Asian-Australasian Journal of

Bioscience and Biotechnology

ISSN 2414-1283 (Print) 2414-6293 (Online)

www.ebupress.com/journal/aajbb

\title{
Article \\ Prevalence and antimicrobial susceptibility patterns of Vibrio cholerae in dairy excreta
}

\author{
Nilofa Eashmen ${ }^{1 \mathrm{a}}$, Mohammad Arif ${ }^{2 \mathrm{a}}$, Basana Sarker $^{1}$, Mir Rowshan Akter ${ }^{1}$ and S. M. Lutful Kabir ${ }^{2 *}$ \\ ${ }^{1}$ Department of Microbiology, Hajee Mohammad Danesh Science and Technology University, Dinajpur-5200, \\ Bangladesh \\ ${ }^{2}$ Department of Microbiology and Hygiene, Bangladesh Agricultural University, Mymensingh-2202, \\ Bangladesh
}

${ }^{a}$ Nilofa Eashmen and Mohammad Arif contributed equally to this work

*Corresponding author: Professor Dr. S. M. Lutful Kabir, Department of Microbiology and Hygiene, Bangladesh Agricultural University, Mymensingh-2202, Bangladesh. Phone: +8801754987218; E-mail: lkabir79@bau.edu.bd

Received: 31 March 2021/Accepted: 28 April 2021/ Published: 30 April 2021

\begin{abstract}
Vibrio cholerae is a major etiological agent of human diarrhoea and has become epidemic across the world in the recent past. A cross-sectional study was conducted to assess the prevalence of $V$. cholerae from dairy excreta along with antimicrobial resistant status of the isolates. A total 50 samples were collected from 50 different household manure pit located at Bangladesh Agriculture University (BAU) surrounding area, Mymensingh. Alkaline peptone water was used for enrichment of the samples followed by inoculation onto thiosulfate citrate bile salt sucrose (TCBS) agar media for the isolation of Vibrio spp., which were further confirmed via Vibrio genus specific molecular assay. Biochemical tests were performed to identify V. cholerae from the isolates of Vibrio spp. Out of 50 samples 17 (34\%) were confirmed as Vibrio spp. as they produced characteristic yellow colonies on TCBS agar and had found to possess recombinase A gene that confirmed the identity of Vibrio spp. From this 17 Vibrio isolates, 6 (12\% in total from 50 samples) were identified as $V$. cholerae based on different biochemical tests. All the isolates fermented glucose, maltose, sucrose and mannitol with the production of only acid. The isolates were positive in oxidase, gelatinase, methyl-red (MR) and indole test, but negative in case of voges-proskaure (VP) test. In antimicrobial susceptibility testing, V. cholerae isolates showed $100 \%$ sensitivity to gentamycin, chloramphenicol and tetracycline with moderate sensitivity to ciprofloxacin and co-trimoxazole. A high level of resistance was observed to ampicillin (100\%) followed by moderate resistance to erythromycin and imipenem. In the present study about $33.33 \%(\mathrm{n}=2)$ of 6 isolated $V$. cholerae were found to be multidrug resistant (MDR) as they demonstrated resistant against 3 antimicrobial agents. The findings of this study substantiate the presence of MDR V. cholerae in the dairy excreta, which indicates the role of domestic animals to serve as a reservoir that might pose a health risk to human. Hygienic management of animal waste is needed to reduce the burden of human illness.
\end{abstract}

Keywords: Vibrio cholerae; diarrhoea; dairy excreta; multidrug resistant; antimicrobial susceptibility

\section{Introduction}

Globally diarrhoeal diseases including cholera, are considered as a leading cause of death of children under 5 years of age as well as the morbidity in adults (Bryce et al., 2005; Shrestha et al., 2015) of which 10\% contribute from the low and middle-income countries, including Bangladesh (WHO, 2021). Vibrio cholerae is the causative agent of cholera. Being a genetically versatile bacterial species, Vibrio cholerae has more than two hundred serogroups on the basis of the somatic $\mathrm{O}$ antigens (Vu et al., 2018) among which $\mathrm{O} 1$ and $\mathrm{O} 139$ are two 
major virulent strains that have the potential to cause an epidemic (Mehrabadi et al., 2012). Classical and El Tor, two biotypes of $V$. cholerae $\mathrm{O} 1$ are documented as the causative agents of the sixth and the seventh pandemics respectively (Ramamurthy and Nair, 2010). V. cholerae O1 is still the prime cause of many outbreak in Asian countries from where it is frequently isolated (Shrestha et al., 2015). Moreover, multiple antibiotic resistant (MAR) $V$. cholerae O1 El Tor biotype triggered the seventh cholera pandemic that expanded rapidly from Indonesia to Bangladesh, India, Iraq, and Iran (Safa et al., 2010).

Approximately 1.3 billion people of the world are at risk of cholera where Bangladesh occupies a larger portion (Islam et al., 2019). A recent update reveals that around 66 million people of Bangladesh are living with the risk of cholera where the estimated incidence is about 1.64 per thousand people (Ali et al., 2015). In Bangladesh, about 109,000 cases of cholera are estimated yearly, where the case fatality rate is 3\% (Ali et al., 2015). Insufficient sanitation, poor access to pure drinking water and poor socio-economic status are considered as the major predisposing factors of cholera outbreaks. Infection of cholera happens mainly through fecal-oral route especially ingestion of faecally contaminated foods or water (Shrestha et al., 2015). In the small intestine, $V$. cholerae secrets enterotoxin known as cholera toxin, which results in excessive release of water and electrolytes into the gut lumen causing massive fluid loss, diarrhea and vomiting (Maheshwari et al., 2011).

Human and animal excreta harbor various enteric pathogens including V. cholerae (Delahoy et al., 2018) which transmit diseases predominantly in children and cause deaths due to diarrhea in the developing countries including Bangladesh (Uddin et al., 2012). At present, access to improved sanitation is keeping human away from the risk of their own excreta but not from animal waste. In developing countries, animals have frequent contact with humans and that is why animal feces may impose substantial burden of diseases in humans (Delahoy et al., 2018). Therefore, lack of attention on the hygienic management of animal waste may arise a dangerous situation.

A few studies conducted in Bangladesh to explore sparsely the burden of $V$. cholerae from animal excreta (Akond et al., 2008; Uddin et al., 2012; Islam et al., 2013). However, the present study was performed to figure out the role of animals to act as a reservoir of $V$. cholerae. Therefore, this study was conducted to investigate: (1) the prevalence, (2) identification and (3) antimicrobial resistance status of Vibrio cholerae from fecal materials of cattle of Mymensingh sadar upazila. The outcome may assist physician to the proper antibiotic choice for the therapeutic purpose and simultaneously provide significance to public health decision-makers with the more effective management of animal waste to reduce the burden of zoonotic diseases in humans.

\section{Materials and Methods}

\subsection{Ethical statement}

This study doesn't require any ethical statement. Verbal consent was taken during sample collection from farm owners.

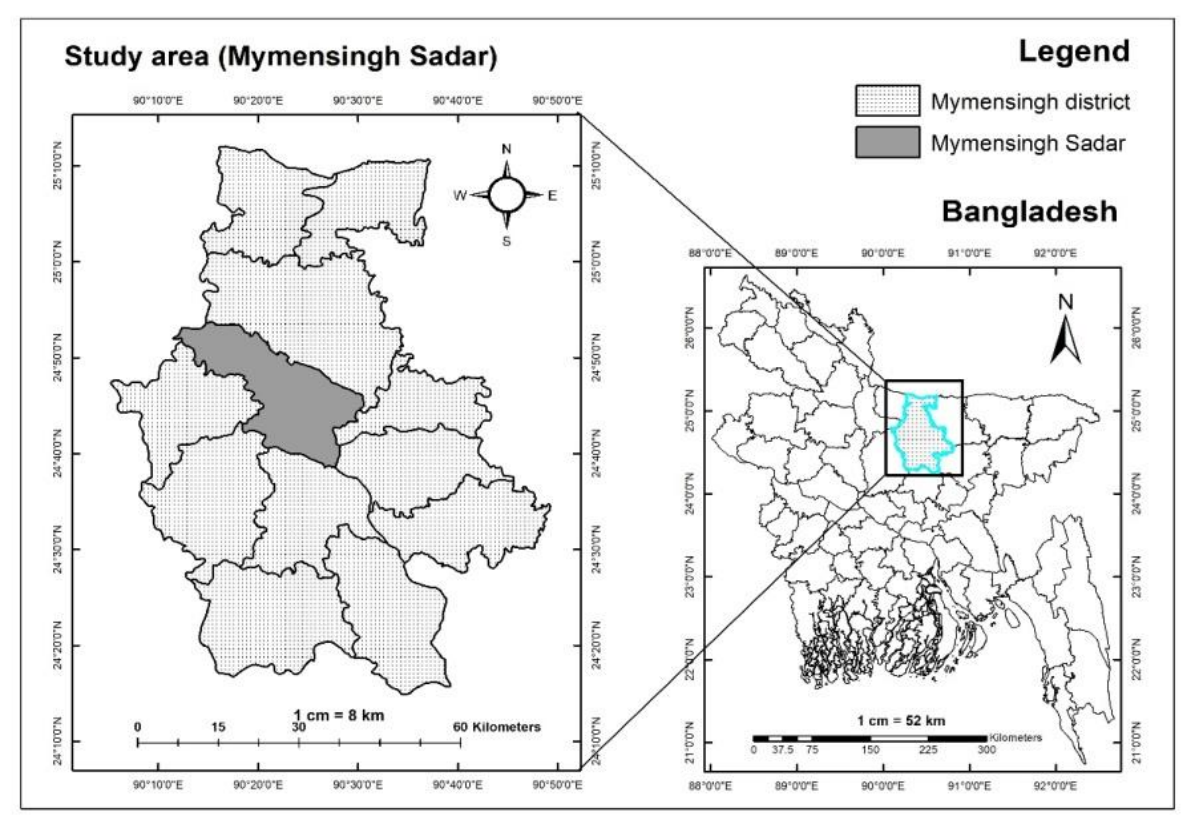

Figure 1. Study area map, created with ArcMap 10.7 software (ESRI, Redlands, California, USA) based on Geographical Information System (GIS). 


\subsection{Study area}

The present study was carried out at the surrounding area of Bangladesh Agricultural University (BAU), Mymensingh Sadar Upazila (24.42 $\left.{ }^{\circ} \mathrm{N}, 90.25^{\circ} \mathrm{E}\right)$ of the Mymensingh district of Bangladesh (Figure 1) during the period of July 2019 to November 2019. In this area, people are mostly live on agriculture or animal rearing. In addition, different indigenous and cross breed of cattle are frequently available in this area.

\subsection{Collection of samples}

Samples were collected from 50 different household manure pit located in Bangladesh Agriculture University (BAU) surrounding area. Sample was collected from different location of a manure pit to make a pooled sample from each household cattle farm. Samples were taken with the help of sterile cotton buds and dipped into sterile normal saline. Collected samples were transported immediately to the bacteriology laboratory of the Department of Microbiology and Hygiene, BAU, Mymensingh, for bacterial isolation and identification.

\subsection{Isolation of Vibrio spp.}

Isolation of Vibrio spp. was performed following the procedure described by Shrestha et al. (2015) with some modifications adopted from Uddin et al. (2012). Accordingly, samples were enriched in alkaline peptone water (APW) (HiMedia, India) at $37{ }^{\circ} \mathrm{C}$ for $8 \mathrm{~h}$. Enriched samples were then subjected to 10 fold serial dilution up to $10^{-4}$. From $10^{-2}, 10^{-3}$ and $10^{-4}$ dilutions, $0.1 \mathrm{ml}$ samples were inoculated onto thiosulfate citrate bile salt sucrose (TCBS) agar (HiMedia, India) and incubated at $37{ }^{\circ} \mathrm{C}$ for $24 \mathrm{~h}$. After incubation, sucrose fermenting yellow colored colonies on TCBS agar were further streaked onto the same agar and incubated at $37{ }^{\circ} \mathrm{C}$ for $24 \mathrm{~h}$. Characteristic yellow colored colonies were selected and stained to observe the morphology of the bacteria.

\subsection{Molecular detection of Vibrio spp.}

Template DNA for the identification of Vibrio spp. was carried out by boiling method following the procedure described by Sarker et al. (2020). PCR was performed as per the method described previously by Kim et al. (2015) with some modifications. Amplification of recombinase A gene was performed to identify Vibrio genus with a DNA thermal cycler (Thermo cycler, ASTEC, Japan) using the published primers. The list of primers is shown in Table 1. PCR reactions were carried out with $20 \mu \mathrm{l}$ volume that included $10 \mu 1$ master-mix (Promega, USA), $1 \mu$ forward primer (Macrogen Inc., Korea), $1 \mu$ l reverse primer (Macrogen Inc., Korea), $2 \mu 1$ DNA template and $6 \mu \mathrm{l}$ deionized water. The thermocycling conditions consisted of an initial denaturation at $94{ }^{\circ} \mathrm{C}$ for $5 \mathrm{~min}$, followed by 25 cycles of $30 \mathrm{~s}$ denaturation at $94{ }^{\circ} \mathrm{C}, 30 \mathrm{~s}$ annealing at $60{ }^{\circ} \mathrm{C}$ and $30 \mathrm{~s}$ extension at $72{ }^{\circ} \mathrm{C}$. Thereafter, a final extension of $10 \mathrm{~min}$ at $72{ }^{\circ} \mathrm{C}$ ended up the PCR reaction. PCR products were taken for gel electrophoresis with $1.5 \%$ agarose gel at 100 volts for $45 \mathrm{~min}$. Then the gel was submerged in ethidium bromide having final concentration of $4 \mathrm{mg} / \mathrm{ml}$ for $15 \mathrm{~min}$ maintaining a dark condition followed by washing with distilled water for $5 \mathrm{~min}$. Afterwards, the DNA was visualized under UV transilluminator (Biometry, Germany).

\section{Table 1. Primers used for the molecular detection of Vibrio genus.}

\begin{tabular}{llll}
\hline Primers & Sequence $\left(\mathbf{5}^{\prime} \mathbf{- 3}^{\prime}\right)^{\mathbf{a}}$ & Amplicon size (bp) & Reference \\
\hline VG C2694352 F46 & GTC ARA TTG AAA ARC ART TYG GTA AAG G & \multirow{2}{*}{689} & Kim et al., \\
VG C2694352 R734 & ACY TTR ATR CGN GTT TCR TTR CC & & 2015 \\
\hline
\end{tabular}

${ }^{\mathrm{a}}$ Mixed base: $\mathrm{R}=\mathrm{A}+\mathrm{G} ; \mathrm{Y}=\mathrm{C}+\mathrm{T} ; \mathrm{N}=\mathrm{A}+\mathrm{C}+\mathrm{G}+\mathrm{T}$

\subsection{Identification of Vibrio cholerae}

Suspected Vibrio isolates were screened for the presence of cytochrome oxidase and gelatinase activity by subculturing onto gelatin agar media. Isolates, found to harbor cytochrome oxidase and showed gelatinase activity were selected to perform further confirmation by other biochemical tests like motility test, sugar fermentation test, triple sugar iron (TSI) agar test, indole test, urease test, Voges-Proskauer (VP) test and salt tolerance test according to 'Microbiological Laboratory Manual' (Cappuccino and Sherman, 1996).

\subsection{Antimicrobial susceptibility testing}

All the isolates of $V$. cholerae were subjected to antibiotic susceptibility against eight antibacterial drugs of eight different antibiotic classess by modified Kirby-Bauer method (Bauer et al., 1996) on Mueller-Hinton Agar (HiMedia, India) using antibiotic discs (Oxoid, England) including ampicillin $(10 \mu \mathrm{g})$, chloramphenicol $(30 \mu \mathrm{g})$, co-trimoxazole $(25 \mu \mathrm{g})$, ciprofloxacin $(5 \mu \mathrm{g})$, erythromycin $(15 \mu \mathrm{g})$, gentamycin $(10 \mu \mathrm{g})$, imipenem $(10 \mu \mathrm{g})$ and tetracycline $(30 \mu \mathrm{g})$. The zones of growth inhibition connected with the zone diameter for individual 
antimicrobial agents were then interpreted as susceptible, intermediate or resistant categories according to the interpretation table supplied by the manufacturer (Oxoid limited, England). All interpretations were confirmed by the completion of all disk diffusion tests for three times. In the present study, isolates showing resistant to three or more classes of antibiotics were referred to as Multidrug Resistant (MDR) bacteria as described earlier (Sweeney et al., 2018).

\section{Results}

\subsection{Prevalence of Vibrio cholerae}

A total of 50 different dairy excreta samples from 50 dairy farms of Bangladesh Agricultural University (BAU) surrounding area, Mymensingh were screened to isolate and identify Vibrio cholerae. The study estimated an overall prevalence of $V$. cholerae as $12 \%$ (6 positive out of 50 samples) including all assessment methods though culture, biochemical tests and finally molecular detection (Table 2). Out of 50 samples, a total of 28 (56\%) isolates showed positive growth on thiosulfate citrate bile salt (TCBS) agar plates (HiMedia, India) and produced small (2-3 mm), raised, circular, yellow (21 out of 28 culture positive case) as well as green, round, 2$3 \mathrm{~mm}$ diameter colonies ( 7 out of 28 culture positive case). However, out of 28 culture positive isolates, 17 (60.71\%) were confirmed as Vibrio spp. through polymerase chain reaction (PCR) targeting recombinase A gene of Vibrio. Furthermore, 6 (35.29\%) out of 17 positive Vibrio spp. were confirmed as Vibrio cholerae based on different biochemical tests and remaining $11(64.70 \%)$ were suspected as other Vibrio spp. (Figure 2).

Table 2. Frequency distribution of the Vibrio isolates from the 50 samples.

\begin{tabular}{l|l|l|l|l|l}
\hline Sample type & $\begin{array}{l}\text { No. (\%) of } \\
\text { sample } \\
\text { tested }\end{array}$ & $\begin{array}{l}\text { No. (\%) of } \\
\text { isolates showed } \\
\text { positive cultural } \\
\text { characteristics }\end{array}$ & $\begin{array}{l}\text { No. (\%) of isolates } \\
\text { confirmed as } \\
\text { Vibrio spp. through } \\
\text { PCR }\end{array}$ & $\begin{array}{l}\text { No. (\%) of isolates } \\
\text { confirmed as Vibrio } \\
\text { cholerae based on } \\
\text { biochemical tests }\end{array}$ & $\begin{array}{l}\text { No. (\%) of Vibrio } \\
\text { spp. other than } \\
\text { Vibrio cholerae }\end{array}$ \\
\hline Dairy excreta & $50(100)$ & $28(56)$ & $17(34)$ & $6(12)$ & $11(22)$ \\
\hline
\end{tabular}



Figure 2. Percentage of Vibrio cholerae and other Vibrio spp. from 17 positive Vibrio isolates.

\subsection{Molecular identification of Vibrio spp. by PCR}

DNA extracted from all culture positive samples were screened through PCR assay for specific identification of Vibrio genus. Amplification of recombinase A gene of Vibrio spp. from the isolated genomic DNA produced 689 bp (Figure 3) that confirmed the identity of Vibrio genus.

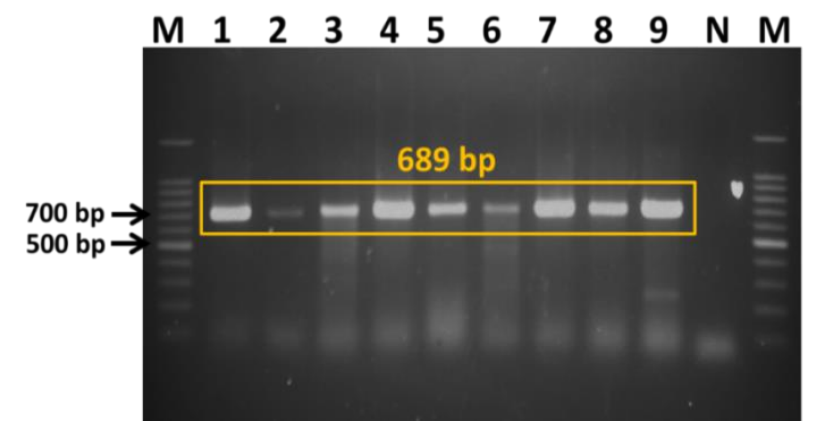

Figure 3. Recombinase A gene based PCR of Vibrio genus showing positive band at 689 bp. Here lane M: 100 bp DNA lader; lane N: Negative control; Lane 1-9: Positive sample of Vibrio spp. 


\subsection{Biochemical characterization of Vibrio cholerae}

All the isolates, confirmed via PCR were further identified as Vibrio cholerae based on the morphological and biochemical characteristics. Microscopically, $V$. cholerae appeared as gram negative, curved rod, motile organism. All the $V$. cholerae isolates were found positive in catalase, oxidase, gelatinase, MR and indole test. However, negative reactions were noticed in VP, Urease and $\mathrm{H}_{2} \mathrm{~S}$ production test. They exhibited an acid (yellow) slant and acid (yellow) butt without the production of gas and $\mathrm{H}_{2} \mathrm{~S}$ on TSI agar slant. V. cholerae fermented glucose, sucrose, galactose, maltose, mannitol without gas production but did not ferment lactose. Biochemical characteristics of $V$. cholerae were highlighted in Table 3.

Table 3. Results of biochemical characteristic of isolated Vibrio cholerae.

\begin{tabular}{|c|c|}
\hline Characteristics & Results \\
\hline Gram stain & - \\
\hline Shape & Curved rod \\
\hline Motility & + \\
\hline Oxidase & + \\
\hline Catalase & + \\
\hline Gelatinase test & + \\
\hline Triple Sugar Iron Agar (TSI) & + \\
\hline Methyl-red test & + \\
\hline Voges-Proskaur & - \\
\hline Indole & + \\
\hline Urease & - \\
\hline $\mathrm{H}_{2} \mathrm{~S}$ production & - \\
\hline Arginine dehydrolase & - \\
\hline Lysine and ornithine decarboxylase tests & + \\
\hline \multicolumn{2}{|l|}{ Sugar fermentation test } \\
\hline Glucose & + \\
\hline Lactose & - \\
\hline D-galactose & + \\
\hline Sucrose & + \\
\hline Maltose & + \\
\hline Mannitol & + \\
\hline \multicolumn{2}{|l|}{ Growth in nutrient broth } \\
\hline$+0 \% \mathrm{NaCl}$ & + \\
\hline$+2 \% \mathrm{NaCl}$ & + \\
\hline$+4 \% \mathrm{NaCl}$ & + \\
\hline$+6 \% \mathrm{NaCl}$ & + \\
\hline$+8 \% \mathrm{NaCl}$ & - \\
\hline
\end{tabular}

\subsection{Antibiogram profiles of isolated Vibrio cholerae}

Antibiotic sensitivity tests revealed that all $V$. cholerae isolates $(\mathrm{n}=6)$ were resistant to ampicillin $(100 \%)$. Additionally, $V$. cholerae isolates were resistant to imipenem (83.33\%) and erythromycin (33.33\%). Conversely, all the 6 isolates were found $100 \%$ sensitive to chloramphenicol, gentamicin and tetracycline whereas, $83.33 \%$ to ciprofloxacin. The overall antibiotic resistance profile of the isolated $V$. cholerae is presented in Figure 4. 


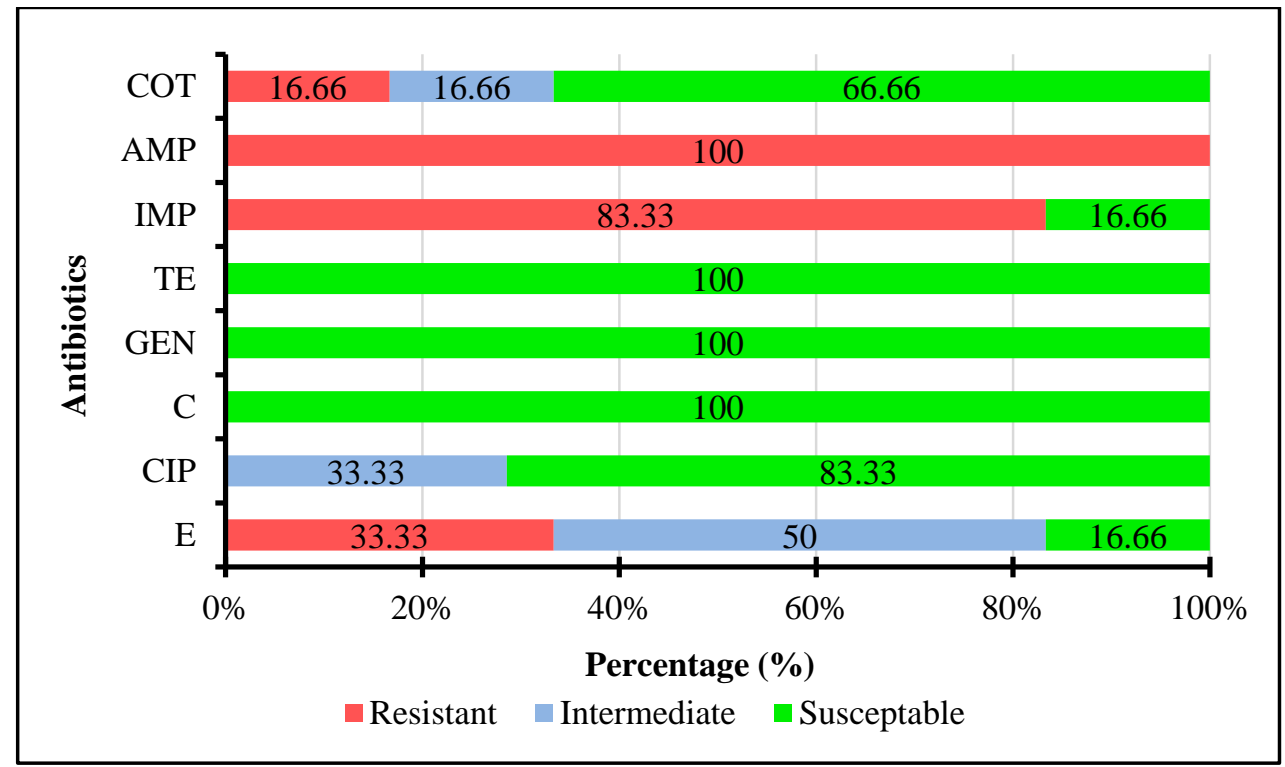

Figure 4. Antibiogram profiles of $V$. cholerae isolated from dairy excreta. COT = Co-Trimoxazole; AMP = Ampicillin; IMP = Imipenem; TE = Tetracycline; GEN = Gentamicin; $\mathbf{C}=$ Chloramphenicol; $\mathbf{C I P}=$ Ciprofloxacin; E = Erythromycin.

\subsection{Distribution of MDR Vibrio cholerae}

In the present study, we had found $2(33.33 \%)$ out of $6(100 \%) \mathrm{V}$. cholerae isolates exhibiting resistance against at least three antibiotic agents (Table 4). Each of the two isolates was found resistant against three antibiotics of three different classes. Two isolates demonstrated two different antimicrobial resistance pattern, E-IMP-AMP and IMP-AMP-COT respectively.

Table 4. Multidrug resistance (MDR) profiles of $V$. cholerae $(n=6)$ isolated from dairy excreta.

\begin{tabular}{lllll}
\hline $\begin{array}{l}\text { Pattern } \\
\text { no. }\end{array}$ & $\begin{array}{l}\text { Antibiotic resistance } \\
\text { patterns }\end{array}$ & $\begin{array}{l}\text { No. of antibiotics } \\
\text { (classes) }\end{array}$ & $\begin{array}{l}\text { No. (\%) of MDR } \\
\text { isolates }\end{array}$ & $\begin{array}{l}\text { Overall no. (\%) of } \\
\text { MDR isolates }\end{array}$ \\
\hline 1 & E- IMP- AMP & $3(3)$ & $1(16.66)$ & $2(33.33)$ \\
2 & IMP- AMP-COT & $3(3)$ & $1(16.66)$ & \\
\hline
\end{tabular}

\section{Discussion}

Contaminated food and water are to be observed as the potential sources for cholera transmission. Cholera infection in human often progress with diarrhea where contaminated water from the liquid stool of diarrheic patient further continue the transmission cycle (Uddin et al., 2012). It has been evidenced that other than the human stool, animal and poultry excreta can also act as the reservoir of cholera infection (Uddin et al., 2012; Akond et al., 2008; Sanyal et al., 1974).

In the present study, we evaluated prevalence, molecular and biochemical confirmation with antimicrobial resistant pattern of Vibrio cholerae isolated from 50 dairy excreta samples that had been collected from individual cattle farm of BAU surrounding area. The occurrence of V. cholerae was found $12 \%$ from the fecal sample of cattle. This finding is comparable with the finding of some other similar study. Uddin et al. (2012) found $V$. cholerae to be present in cow dung, poultry and human excreta and the concentration of $V$. cholerae was found to be higher in human excreta. According to Akond et al. (2008) V. cholerae was isolated as $16 \%$ and $24 \%$ from each 50 samples of cloacal swab and intestinal fluid of poultry respectively. Out of 786 samples from cow, Sanyal et al. (1974) recorded 37 (4.71\%) positive case for $V$. cholerae. However, $V$. cholerae recovered from some other natural sources has been documented also like $12 \%$ from human stool in Bangladesh (Zereen $e t$ al., 2019), 6.3\% from retail seafood (Vu et al., 2018), 0.7\% from shrimp samples (Ahmed et al., 2018), 4.88\% from human diarrheic sample (Shrestha et al., 2015) and 30.4\% from seafood of Nigeria (Adebayo-Tayo et al., 2011). Variations in the occurrence of $V$. cholerae may be the different sample types and geographical locations. We could not compare our study finding of the occurrence of $V$. cholerae in great extent due to lack of reference data from animal sources. Vibrio spp. can be found naturally in an aquatic environment, more precisely the evidence of these organisms in raw seafood is very common (Adebayo-Tayo et al., 2011). However, Sanyal et 
al. (1974) had clearly documented that $V$. cholerae can exist in nonhuman reservoirs such as household cows, goats, dogs, and chickens. Moreover, these reservoirs may play role in the transmission cycle of the infection in humans.

All the culture positive isolates were confirmed as Vibrio spp. through molecular assay. 17 isolates out of 50 samples were confirmed as Vibrio spp. though a genus specific PCR assay. Recombinase A gene was targeted for the identification of vibrio genus, which was documented by Kim et al. (2015). Kim et al. (2015) described a newly developed multiplex PCR for the detection of Vibrio genus along with five pathogenic Vibrio species where he evaluated 117 strains and all the isolates were identified to be Vibrio species. Unfortunately the present study did not adopt the entire multiplex PCR method due to some limitations, rather we have followed the molecular identification method of Vibrio genus and found the similar type of result.

In the present study, $6(12 \%)$ isolates of 17 Vibrio spp. were confirmed to be Vibrio cholerae based on cultural, morphological and biochemical characteristics. Due to the lack of molecular identification facilities, biochemical methods were solely performed to identify $V$. cholerae. Morphologically the isolated colonies showed small $(2-3 \mathrm{~mm})$, circular, and yellow color flattened colonies on thiosulfate citrate bile salts sucrose (TCBS) agar plates (HiMedia, India), previously described by Zereen et al. (2019) and Uddin et al. (2012). Microscopically isolated V. cholerae was observed as motile organism (Zereen et al., 2019). Dua et al. (2017) described four traits to identify $V$. cholerae (fermentation of sucrose, non-requirement of external $\mathrm{NaCl}$ for the growth, absence of esculin and presence of oxidase), which are also reflected in the present study. Our results of sugar fermentation test match with the findings of Udoh and Itah (2012) who had found glucose, sucrose, mannitol, D-mannose, D-galactose to be fermented by $V$. cholerae whereas no fermentation was observed for lactose. Uddin et al. (2012) exhibited an acid (yellow) slant and acid (yellow) butt without the production of gas and $\mathrm{H}_{2} \mathrm{~S}$ on TSI agar slant, which are also in agreement with the present study.

Antibiotic resistance is considered as a major public health problem. The irrational and misuse of antimicrobial agents contributed to the development and spread of antibiotic-resistant pathogens in animals and humans (Simonsen et al., 2004). In response to this malpractice, WHO has stated AMR (antimicrobial resistance) as a serious public health concern across the world (Ventola, 2015). All the isolated $V$. cholerae strains in this study were found resistant to ampicillin, suggesting this drug is inefficient in the treatment of cholera. Das et al. (2011) and Shrestha et al. (2015) also reported $100 \%$ resistance to the above antibiotic. Harris et al. (2012) and Kansakar et al. (2011) sparsely documented macrolide resistance in their studies. However, a slightly high level erythromycin resistance (33.33\% resistance with 50\% intermediate) was observed in our study which is in line with the finding of Akond et al. (2008) and Shrestha et al. (2015). Our study identified imipenem resistant $(83.33 \%) V$. cholerae, which may cause a threat to public health as carbapenem group of antibiotic is mostly applied in the serious infectious cases of human (Islam et al., 2021). This result contrast with the finding of Uddin et al. (2012). Resistance to imipenem may have revealed due to the transmission of bacteria from human sources, as carbapenems are not authorized for use in livestock (Poirel et al., 2014). Further studies at the molecular level are required to follow up on these findings. Additionally, all isolated strains showed $100 \%$ sensitivity to chloramphenicol, gentamicin and tetracycline whereas, $83.33 \%$ to ciprofloxacin which may be effective therapeutic agents for the treatment of cholera. This finding support the result of previously conducted studies (Shrestha et al., 2015; Akond et al., 2008). However, Akond et al. (2008) and Shah et al. (2012) reported $100 \%$ and $81.8 \%$ resistance to tetracycline respectively, Uddin et al. (2012) reported 100\% resistance to tetracyclin and chloramphenicol, Garg et al. (2000) reported high-level resistance to chloramphenicol in India. These findings contrasted with our findings.

The choice of drugs, practiced globally over the years for controlling $V$. cholerae serogroup $\mathrm{O} 1$ infection are mostly tetracyclines, fluoroquinolones and macrolides (Leibovici-Weissman et al., 2014). Additionally, according to WHO- erythromycin, trimethoprim-sulphamethoxazole, and chloramphenicol have also been found effective in case of treating the infectious cholera agents (Faruque et al., 2007). However, resistance to all these commonly used drugs has been reported as a result of chromosomal mutations or by gaining mobile genetic elements like plasmids, transposons etc. (Ceccarelli et al., 2016). In Bangladesh, although tetracycline and doxycycline have long been considered as the antibiotics of choice for cholera (Faruque et al., 2007), clinicians are also prescribing other WHO recommended drugs. So, this might be the cause that the present study showed some isolated $V$. cholerae strain resistant to erythromycin and co-trimoxazole. But, it's a message of hope that our study evidenced the effectiveness of tetracycline, ciprofloxacin and chloramphenicol in treating the infectious case with $V$. cholerae.

It is a matter of concern that out of 6 isolated $V$. cholerae, $2(2 / 6,33.33 \%)$ were found to be multidrug resistance (MDR) in the present study. Shrestha et al. (2015) and Roy et al. (2012) reported 100\% MDR V. cholerae from human stool samples, which contrasted with the present study. Whereas, Garbern et al. (2021) documented 
28.1\% MDR $V$. cholerae from same type of samples in Bangladesh which nearly matched with the present study. However, No document was retrieved about MDR V. cholerae from animal samples.

MDR cholera epidemics have already been reported previously from Bangladesh (Faruque et al., 2006). Moreover, epidemics of MDR cholera (both classical and El Tor biotypes) have also been reported worldwide (Mandal et al., 2011). Therefore, as a potential source of cholera, human can play a vital role in the transmission of $V$. cholerae in livestock, since cattle, buffalo, goat, sheep and poultry are habited in close contact of human in Bangladesh. Although Delahoy et al. (2018) documented a limited or no transmission of cholera in human by animal feces, the risk can not be ignored as pathogenic cholera strain are being recovered from the animal feces (Uddin et al., 2012; Akond et al., 2008). For additional survival advantages newly emerged cholera strains are being evolved to replace the prevailing epidemic strains through genetic changes (Faruque et al., 2006) like spontaneous mutation or horizontal transfer of resistance genes (Shrestha et al., 2015).

This present study is the first approach to highlight the role of animals as a reservoir of cholera infection which is supported by the isolation and identification of $V$. cholerae from the animal waste. The findings of the present study may assist the clinician to select appropriate antibiotics for serious cholera cases and simultaneously provide significance to public health decision-makers with the more effective management of animal waste to reduce the burden of zoonotic diseases in humans.

The main limitation of this study was the time and fund constrain. As a result, molecular detection of $V$. cholerae was not attained, rather identification was solely dependent on biochemical tests. Further studies are badly needed to characterize these isolates through molecular assay to find out whether they are virulent for humans or have the potential to cause an epidemic.

\section{Conclusions}

Vibrio cholerae is one of the major agents associated with diarrhoea outbreaks in Bangladesh. Present study isolated MDR $V$. cholerae from cattle feces, evidencing the possibility of animals being served as the reservoir of cholera that might pose substantial risk to human health if these MDR bacteria enters into the food chain. Inadequate management of animal feces from human domestic environments can happen fecal-oral transmission of zoonotic pathogens including $V$. cholerae due to the poor sanitation practice. Therefore, composting of animal and poultry feces can be a better managemental strategy which will lower the risk of spreading potential pathogens and reduce environmental pollutions through hygienic waste disposal.

\section{Acknowledgements}

The authors would like to thank all the staffs of the Department of Microbiology and Hygiene, Bangladesh Agricultural University, Mymensingh-2202, Bangladesh for providing continuous support and sincere cooperation.

\section{Conflict of interest}

None to declare.

\section{Authors' Contribution}

Mohammad Arif and S. M. Lutful Kabir designed the experiment. Nilofa Eashmen, Mohammad Arif and Basana Sarker collected the samples and conducted an experiment. Mohammad Arif drafted the first version of the manuscript. S. M. Lutful Kabir and Mir Rowshan Akter critically reviewed the article and finally approved for publication.

\section{References}

Adebayo-Tayo BC, IO Okonko, CU Esen, NN Odu, CC Onoh and NJ Igwiloh, 2011. Incidence of potentially pathogenic Vibrio spp. in fresh seafood from Itu Creek in Uyo, Akwa Ibom State, Nigeria. World Appl. Sci. J., 15: 985-991.

Ahmed HA, RS Abdelazim, RM Gharieb, RM Abou Elez and MA Awadallah, 2018. Prevalence of antibiotic resistant $V$. parahaemolyticus and $V$. cholerae in fish and humans with special reference to virulotyping and genotyping of $V$. parahaemolyticus. Slov. Vet. Res., 55: 251-262.

Akond MA, S Alam, SM Hasan, SN Uddin and M Shirin, 2008. Antibiotic resistance of Vibrio cholerae from poultry sources of Dhaka, Bangladesh. Advan. Biol. Res., 2: 60-67.

Ali M, AR Nelson, AL Lopez and DA Sack, 2015. Updated global burden of cholera in endemic countries. PLOS Negl. Trop. Dis., 9: e0003832. 
Bauer AW, WMM Kirby, JC Sherris and M Turck, 1996. Antibiotic susceptibility testing by a standardized single disk method. Am. J. Clin. Pathol., 45: 493-496.

Bryce J, C Boschi-Pinto, K Shibuya and RE Black, 2005. WHO estimates of the causes of death in children. Lancet, 365: 1147-1152.

Cappuccino GJ and ND Sherman, 1996. Microbiology: A laboratory manual $5^{\text {th }}$ ed. The Benjamin/ Publishing Co., Inc., Menlo Park, California.

Ceccarelli D, M Alam, A Huq and RR Colwell, 2016. Reduced susceptibility to extended-spectrum $\beta$-lactams in Vibrio cholerae isolated in Bangladesh. Front. Public Health, 4: 231.

Das S, S Choudhry, R Saha, VG Ramachandran, K Kaur and BL Sarkar, 2011. Emergence of multiple drug resistance Vibrio cholerae O1 in East Delhi. J. Infect. Dev. Ctries., 5: 294-298.

Delahoy MJ, B Wodnik, L McAliley, G Penakalapati, J Swarthout, MC Freeman and K Levy, 2018. Pathogens transmitted in animal feces in low-and middle-income countries. Int. J. Hyg. Environ. Health, 221: 661-676.

Dua P, A Karmakar, K Dutta and C Ghosh, 2017. A simple procedure for isolation, identification and characterization of Vibrio cholerae from clinical samples. Int. J. Pharma. Bio. Sci., 8: 57-64.

Faruque AS, K Alam, MA Malek, MG Khan, S Ahmed, D Saha, WA Khan, GB Nair, MA Salam, SP Luby and DA Sack, 2007. Emergence of multidrug-resistant strain of Vibrio cholerae O1 in Bangladesh and reversal of their susceptibility to tetracycline after two years. J. Health Popul. Nutr., 25: 241-243.

Faruque SM, MJ Islam, QS Ahmad, K Biswas, AS Faruque, GB Nair, RB Sack, DA Sack and JJ Mekalanos, 2006. An improved technique for isolation of environmental Vibrio cholerae with epidemic potential: monitoring the emergence of a multiple-antibiotic-resistant epidemic strain in Bangladesh. J. Infect. Dis., 193: 1029-1036.

Garbern SC, TC Chu, P Yang, M Gainey, S Nasrin, S Kanekar, K Qu, EJ Nelson, DT Leung, D Ahmed and CH Schmid, 2021. Clinical and socio-environmental determinants of multidrug-resistant Vibrio cholerae 01 in older children and adults in Bangladesh. Int. J. Infect. Dis., 105: 436-441.

Garg P, S Chakraborty, I Basu, S Datta, K Rajendran, T Bhattacharya, S Yamasaki, SK Bhattacharya, Y Takeda, GB Nair and T Ramamurthy, 2000. Expanding multiple antibiotic resistance among clinical strains of Vibrio cholerae isolated from 1992-7 in Calcutta, India. Epidemiol. Infect., 124: 393-399.

Harris JF, ET Ryan and SB Calderwood, 2012. Cholera. Lancet, 379: 2466-2476.

Islam KMI, SML Kabir, S Saha and MSR Khan, 2013. Prevalence and antimicrobial resistance patterns of Vibrio Cholerae from Bangladesh Agricultural University dairy farm. Int. J. Med. Sci. Biotechnol.. International Journal of Medical Sciences and Biotechnology, 1: 13-25.

Islam MS, MMH Nayeem, MA Sobur, S Ievy, MA Islam, S Rahman, MA Kafi, HM Ashour and MT Rahman, 2021. Virulence determinants and multidrug resistance of Escherichia coli isolated from migratory birds. Antibiotics, 10: 190.

Islam MT, AI Khan, MA Sayeed, J Amin, K Islam, N Alam, N Sultana, N Jahan, MM Rashid, ZH Khan and MI Zion, 2019. Field evaluation of a locally produced rapid diagnostic test for early detection of cholera in Bangladesh. PLOS Negl. Trop. Dis., 13: e0007124.

Kansakar P, P Baral, S Malla and GR Ghimire, 2011. Antimicrobial susceptibilities of enteric bacterial pathogens isolated in Kathmandu, Nepal, during 2002-2004. J. Infect. Dev. Ctries., 5: 163-168.

Kim HJ, JO Ryu, SY Lee, ES Kim and HY Kim, 2015. Multiplex PCR for detection of the Vibrio genus and five pathogenic Vibrio species with primer sets designed using comparative genomics. BMC Microbiol., 15: 239.

Leibovici-Weissman YA, A Neuberger, R Bitterman, D Sinclair, MA Salam and M Paul, 2014. Antimicrobial drugs for treating cholera. Cochrane Database of Systematic Reviews, 6.

Maheshwari M, K Nelapati and B Kiranmayi, 2011. Vibrio cholerae-a review. Vet. World, 4: 423-428.

Mandal S, MD Mandal and NK Pal, 2011. Cholera: a great global concern. Asian Pac. J. Trop. Med., 4: 573580.

Mehrabadi JF, P Morsali, HR Nejad and AA Fooladi, 2012. Detection of toxigenic Vibrio cholerae with new multiplex PCR. J. Infect. Public Health., 5: 263-267.

Poirel L, R Stephan, V Perreten and P Nordmann, 2014. The carbapenemase threat in the animal world: the wrong culprit. J. Antimicrob. Chemother., 69: 2007-2008.

Ramamurthy T and GB Nair, 2010. Evolving identity of epidemic Vibrio cholerae: past and the present. Sci Cult., 76: 153-159.

Roy S, MV Parande, BG Mantur, S Bhat, R Shinde, AM Parande, RS Meti, MR Chandrasekhar, SD Kholkute, A Saini and M Joshi, 2012. Multidrug-resistant Vibrio cholerae O1 in Belgaum, south India. J. Med. Microbiol., 61: 1574-1579. 
Safa A, GB Nair and RY Kong, 2010. Evolution of new variants of Vibrio cholerae O1. Trends Microbiol., 18: 46-54.

Sanyal SC, SJ Singh, IC Tiwari, PC Sen, SM Marwah, UR Hazarika, H Singh, T Shimada and R Sakazaki, 1974. Role of household animals in maintenance of cholera infection in a community. J. Infect. Dis., 130: 575-579.

Sarker B, M Arif, N Eashmen, MR Akter and SML Kabir, 2020. Isolation, identification and antibiogram profile of Aeromonas hydrophila from broiler chickens in Mymensingh Sadar, Bangladesh. Asian Australas. J. Food Saf. Secur., 4: 22-30.

Shah BK, S Sharma, G Shakya and BP Upadhyay, 2012. Multiple drug resistant Vibrio cholerae, Salmonella and Shigella from Nepalgunj Cholera outbreak and different hospitals of Nepal. Nepalese journal of Biosciences, 2: 31-39.

Shrestha UT, N Adhikari, R Maharjan, MR Banjara, KR Rijal, SR Basnyat and VP Agrawal, 2015. Multidrug resistant Vibrio cholerae $\mathrm{O} 1$ from clinical and environmental samples in Kathmandu city. BMC Infect. Dis., 15: $1-7$.

Simonsen GS, JW Tapsall, B Allegranzi, EA Talbot and S Lazzari, 2004. The antimicrobial resistance containment and surveillance approach-a public health tool. Bull. World Health Organ., 82: 928-934.

Sweeney MT, BV Lubbers, S Schwarz and JL Watts, 2018. Applying definitions for multidrug resistance, extensive drug resistance and pandrug resistance to clinically significant livestock and companion animal bacterial pathogens. J. Antimicrob. Chemother., 73: 1460-1463.

Uddin MA, MW Ullah and R Noor, 2012. Prevalence of Vibrio cholerae in human, poultry, animal excreta and compost samples. Stamford J. Microbiol., 2: 38-41.

Udoh DI and AY Itah, 2012. Prevalence, biotypes and antibiogram of Vibrio associated diarrhoea in some parts of Niger Delta region of Nigeria. Asian J. Epidemiol., 5: 15-21.

Ventola CL, 2015. The antibiotic resistance crisis: part 1: causes and threats. Pharmacy and Therapeutics, 40: 277-283.

Vu TT, T Alter and S Huehn, 2018. Prevalence of Vibrio spp. in retail seafood in Berlin, Germany. J. Food Prot., 81: 593-597.

World Health Organization (WHO), 2021. Cholera. Available at: https://www.who.int/en/news-room/factsheets/detail/cholera.

Zereen F, S Akter, MA Sobur, MT Hossain and MT Rahman, 2019. Molecular detection of Vibrio cholerae from human stool collected from SK Hospital, Mymensingh, and their antibiogram. J. Adv. Vet. Anim. Res., 6: 451. 